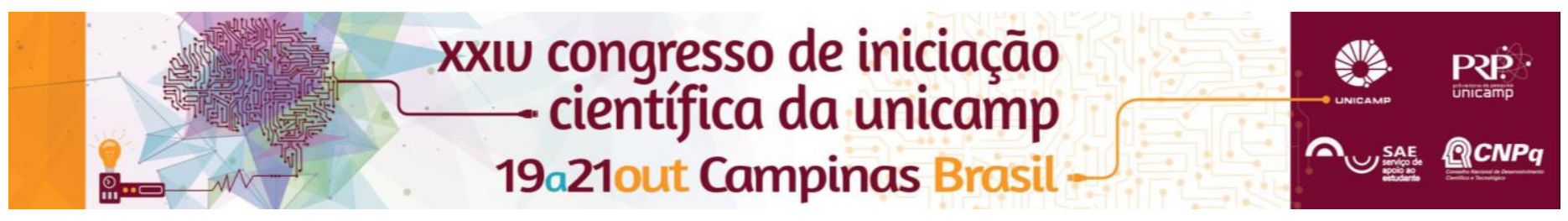

\title{
Caracterização da expressão de interleucina-6 (IL-6) em neurônios hipotalâmicos
}

\author{
Thaís P. do Prado*, Vanessa C.D. Bobbo, Albina de F. S. Ramalho, Joseane Morari, Eliana P. de Araújo.
}

\section{Resumo}

O consumo de dieta rica em gordura é comum na cultura ocidental. Além de induzir inflamação, essa dieta ativa vias de sinalização apoptóticas que resultam em morte neuronal em regiões hipotalâmicas envolvidas no controle do balanço energético, contribuindo com o desenvolvimento ou manutenção da obesidade. A interleucina-6 (IL-6) é uma citocina com ação pró- e anti-inflamatória, presente no hipotálamo. Tem se mostrado importante na proteção e manutenção da sobrevivência neuronal em outras regiões do SNC. Assim, o objetivo deste trabalho é caracterizar a expressão de IL-6 em neurônios do hipotálamo de animais expostos a dieta hiperlipídica através da técnica de imunofluorescência de dupla marcação. Os resultados sugerem diminuição na quantidade de IL-6 nos neurônios hipotalâmicos de animais expostos à dieta hiperlipídica, independente do tempo de exposição. Concluímos que o consumo de dieta hiperlipídica pode reduzir a expressão de IL-6 no hipotálamo.

\section{Palavras-chave:}

IL-6, inflamação, neurogênese, hipotálamo

\section{Introdução}

A obesidade é um problema de saúde pública, e fator de risco para o desenvolvimento de outras comorbidades..$^{1,2} \mathrm{~A}$ homeostase energética é controlada pelos hormônios insulina e leptina, que atuam em neurônios anorexigênicos POMC/CART, e neurônios orexigênicos NPY/AgRP. Falhas nessa sinalização podem explicar o desenvolvimento da obesidade. Ácidos graxos saturados presentes na dieta são reconhecidos por receptores Toll-like 4 (TLR-4), induzindo a expressão de citocinas que inibem a sinalização de hormônios e levam a apoptose de neurônios anorexigênicos. , $^{3,4,5}$

Em animais Knockout para Interleucina-6 (IL-6) há diminuição da proteção neuronal. Ao contrário, a exposição a doses elevadas de IL-6 promove regeneração e maior proteção neuronal. Animais obesos induzidos à prática de atividade física apresentam aumento de IL-6 e IL-10 hipotalâmicas, e consequente redução do processo inflamatório e da massa corporal.

Fundamentados nesses estudos, nossa hipótese é de que a IL-6 pode reduzir a inflamação aumentando a neurogênese no hipotálamo.6,7 $\mathrm{O}$ objetivo deste trabalho é caracterizar a distribuição dessa citocina em neurônios do hipotálamo de animais expostos a dieta hiperlipídica (DH).

\section{Resultados e Discussão}

Camundongos Swiss albinus foram divididos em cinco grupos de acordo com o tempo de exposição à dieta hiperlipídica (DH). Animais expostos à $\mathrm{DH}$ apresentaram maior ganho de peso quando comparados aos controles em dieta padrão. Os cérebros dos animais foram extraídos após perfusão com paraformaldeído $4 \%$ e preparados para imunofluorescência de dupla marcação. As imagens foram capturadas usando um microscópio confocal e avaliadas de forma semiquantitativa.

Observou-se maior presença da IL-6 em animais que receberam dieta padrão, em comparação aos animais em DH. Neurônios NPY distribuem-se na região inferior do hipotálamo enquanto neurônios POMC estão mais presentes na região lateral do hipotálamo, ambos colocalizando com a IL-6. Entre os diferentes tempos de exposição à $\mathrm{DH}$ não houve diferença na expressão de
IL-6, sugerindo que mesmo curtos períodos de exposição à $\mathrm{DH}$ podem promover alterações hipotalâmicas.

Figura 1. Imunofluorescência de dupla marcação na região de eminência média de camundongos Swiss.
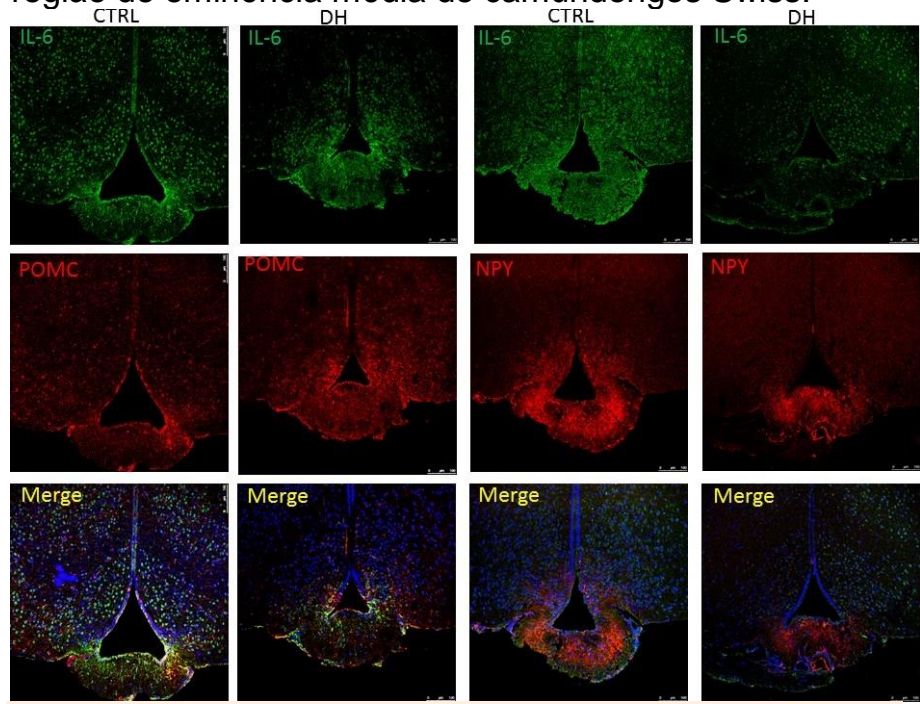

\section{Conclusões}

Concluímos que o consumo de dieta hiperlipídica, independente do tempo de exposição, pode reduzir a expressão de IL-6 no hipotálamo.

\section{Agradecimentos}

Às colaboradoras do projeto pelos momentos de aprendizado e convivência, aos colegas do Laboratório de Sinalização Celular e ao CNPq pela concessão da bolsa.

\footnotetext{
1. Friedman J.M, Halaas J.L. Leptin and the regulation of body weight in mammals. Nature. 22, 763-70. 1998 .

2.Flier JS. Obesity wars: molecular progress confronts an expanding epidemic. Cell. 23,337-50. 2004 Review.

3. Zhang Y, Proenca R, Maffei M, et al. Positional cloning of the mouse obese gene and its human homologue. Nature. 372, 425-432, 1994

4. Velloso L.A. and Schwartz M.W. Altered hypothalamic function in diet-induced obesity. Int J Obes (Lond). 35, 1455-65, 2011

5. Elmquist J.K., Maratos-Flier E., Saper C.B. et al. Unraveling the central nervous system pathways underlying responses to leptin. Nat Neurosci. 1, 445-50. 1998 Review

6. Funk J.A., Gohlke J., Kraft A.D., et al. Voluntary exercise protects hippocampal neurons from trimethyltin injury: possible role ofinterleukin-6 to modulate tumor necrosis factor receptor-mediated neurotoxicity. Brain Behav Immun. Aug;25(6):1063-77, 201123.

7. Pavelko K.D., Howe C.L., Drescher K.M. et al. Interleukin-6 protects anterior horn neurons from lethal virus-induced injury. J Neurosci. Jan 15;23(2):481-92, 200324.
} 